\title{
EL PODER DE LA EVOCACIÓN EN EL AMOR NO ES AMADO DE HÉCTOR BIANCIOTTI
}

POR

\author{
CORINA S. MATHIEU \\ University of Nevada, Las Vegas
}

Comparado a otros narradores hispanoamericanos de su generación, Héctor Bianciotti es un escritor relativamente poco conocido y leído fuera de Francia. Cordobés, se alejó de la Argentina, su tierra natal en 1955, fijó su residencia en París desde 1961 y logró integrarse al panorama literario francés, primero a través de su labor en la prestigiosa editorial Gallimard y luego, por medio del éxito de sus publicaciones.

A primera vista ciertos rasgos nos llevarían a especular que con Biancotti nos hallamos ante un posible continuador de Julio Cortázar. Los dos escritores encontraron en Francia el ambiente propicio para desarrollar su talento literario; ambos dedicaron sus esfuerzos a crear una narrativa de estilo cuidado que sondea la problemática del hombre contemporáneo y ambos son, en aspectos fundamentales, aunque por distintas razones, herederos y continuadores de Jorge L. Borges.

Tales conjeturas, sin embargo, dejan de tener validez al observarse que existe entre los escritores una diferencia radical que se halla ligada, entre otras razones, a la posición de éstos con respecto a su país de origen. Aunque alejado de la Argentina, Cortázar mantuvo un vínculo espiritual con sus compatriotas que se transparenta en personajes y situaciones de su narrativa. Además, con el correr de los años, Cortázar da evidencia de su solidaridad por causas políticas consagradas a la conquista de justicia social en Latino América. El apoyo que su presencia y ayuda económica prestó a esos esfuerzos le ganaron la gratitudy afecto de muchos que vieron en él, no sólo al prestigioso escritor, sino también al hombre comprometido con la causa de los desamparados.

Bianciotti, por el contrario, parece esforzarse en romper todo lazo con su pasado argentino. Así vemos que mientras Cortázar, ciudadano naturalizado francés, no sintió la necesidad de crear en otra lengua, la última novela de Bianciotti, Sin la misericordia de Cristo, premio Femina 1985, fue escrita directamente en francés. El deseo consciente o subconsciente de Bianciotti de reemplazar su lengua por el francés es sin duda parte de su empeño de integración a la sociedad francesa para distanciarse aún más de su pasado argentino. Sus descripciones de la pampa argentina y de la vida del inmigrante 
italiano en el suelo adoptivo reflejan una niñez y una adolescencia desolada donde, a la dureza de los elementos, se le suma el rigor paterno y la inflexibilidad de una rutina importada del Viejo Mundo por los campesinos piamonteses.

Curiosamente, a pesar de su rechazo, Bianciotti no puede liberarse de sus recuerdos, ya que, para él, el escritor es como el antiguo escriba que, inclinado sobre la tableta, transcribe los acontecimientos ocurridos creando la realidad para la posteridad. La postura del autor se evidencia en una entrevista con José Luis Reina: "Creo que la realidad no es real si no se la expresa con palabras"(61). $Y$ concuerda con el periodista, sin titubear, que es la comunicación la que da sentido al lenguaje y constituye el fundamento de la realidad.

El poder del lenguaje para conjurar el pasadoy crear una realidad asentada en la evocación constituye la base de la colección de cuentos El amor no es amado, aparecida en 1983 y objeto de galardones literarios notables como el Premio de la Academia Francesa al mejor libro extranjero de ese mismo año. La colección incluye once cuentos, todos ellos de considerable extensión en los que Bianciotti lentamente, casi de modo proustiano, guía a sus personajes a través de recuerdos significativos que les permiten reflexionar sobre el destino, la creación artística y las relaciones humanas. Pero existen también las sorpresas inesperadas. En esos relatos donde la divagación filosófica, cual fluir de conciencia, parece perderse por los meandros de la mente, también se dan acontecimientos desconcertantes, desagradables, crueles, que recuerdan el terror inspirado por lo mejor de Horacio Quiroga. La diferencia es que en Bianciotti el horror no es nunca el producto de circunstancias fortuitas en las que puede participar la naturaleza, sino el resultado de actos humanos cuya deliberada crueldad no puede menos que causar estupor en el lector.

Dada la aparente temática autobiográfica de "Las iniciales", el primer cuento de la colección, es éste el relato en el cual se puede palpar con más intensidad la naturaleza evocativa de la narrativa de Bianciotti. Al llegar a sus manos una funda de almohadón bordada por su madre setenta años antes, el "yo" reminiscente, que se autodenomina "el escriba" observa detenidamente las iniciales de la bordadora y conjura a la joven campesina que, sin saberlo, ha plasmado su destino en la geométrica labor. Biografía que llama Enrique Anderson-Imbert "a distancia”; por medio de esta técnica el narrador no capta en la fuente viva los instantes del pasado, tal como se desenvolvieron, sino que los analiza, rectifica, clasifica e interpreta desde un punto de vista de observación muy posterior (Anderson Imbert 92). En este caso el “yo" reminiscente, al contacto con dos piezas bordadas por su madre, ya difunta, la funda de soltera y la toalla de confección posterior con las iniciales del futuro esposo, ofrece una imagen de ésta inspirada en dos consideraciones, por un lado la de la mujer cuya vida se halló regida por ancestrales prácticas y, por el otro, la relación filial con "el escriba", su sexto hijo.

El diseño geométrico representa para el narrador el destino de la mujer. "La funda era cuadrada y cuadradas las mallas, y un cuadrado de doce estrellas 
octogonales encerraba las iniciales de la bordadora" (11). Así como las iniciales se hallaban encerradas por doce estrellas, también la vida de la joven estuvo circunscripta por las atávicas costumbres de los campesinos italianos. Casada a los quince años por voluntad de sus padres, la autoridad del esposo reemplazará la de los padres y Teresa se encontrará condenada a la incesante preñez y a la cría "dada la urgencia", nos dice Bianciotti, "en aquellos desiertos, de engendrar mano de obra" (16).

En este homenaje póstumo a la madre, el narrador establece un paralelismo entre la tarea femenina, el bordado de la funda que, a pesar de su humildad, remeda por su concisión geométrica un microcosmo de la armonía cosmogónica presentida por Pitágoras, y la tarea del escriba, esclavo de las palabras, único medio por el cual él dejará testimonio de su existencia. Si en la funda se encuentra sintetizada una vida, ahora el narrador, al exteriorizar sus recuerdos, crea imágenes que reconstruyen esa vida. Imaginación y memoria se aúnan para erigir un altar de palabras al ser querido, pero se muestra reticente con respecto a los resultados y a la imperfección de sus esfuerzos:

Mas, pese a un largo apren dizaje de astucias y cautelas, no he logrado decir nada de usted, apenas nombrarla y referir una que otra cosa - icomo decir lo que se ama? Ya lo ve, no he hecho, al cabo, sino una funda para su memoria, ... (27).

Uno de los cuentos más interesantes y ricos en observaciones referentes a la creación literaria es "Bagheera." En este relato se aprecia la predilección de Bianciotti por escoger situaciones que le permitan desarrollar sus ideas dentro de determinado marco de ficción. El narrador de "Bagheera" es Rudyard Kipling, que en su lecho de muerte repasa los periodos más significativos de su vida. La evocación de la niñez comprende las dos terceras partes del relato, porque la intención del moribundo es identificar las experiencias de su pasado formativo que dejaron una huella indeleble en su espíritu y que constituirán la fuente de su inspiración literaria.

A pesar de que el niño se había visto sometido a numerosas vicisitudes al ser enviado por sus padres a Inglaterra para educarse, su carácter rebelde y terco le permiten sobrevivir. Una vez en el colegio Westward Ho, en el cual él mismo admite, fue pésimo estudiante, su pasión por la lectura se dejó sentir de lleno y, más importante, junto con ello, descubrió, al ganarse la dirección de la revista de la escuela, el poder de la escritura.

Bianciotti encuentra en el conocido autor inglés el protagonista ideal para reiterar su concepción del lenguaje como único medio que el hombre de letras posee para visualizar el mundo y para dejar eterno testimonio de su espiritu estético. Surge además en el cuento, por obvias circunstancias, la relación entre lenguaje e idioma, en este caso el inglés que, a raíz de la política expansionista británica se convirtió, como en siglos anteriores había ocurrido en España, en instrumento de la política imperial. Cabe además señalar que este cuento es un 
homenaje indirecto a Jorge L. Borges. Además de haber escogido a un autor por el cual Borges siempre demostró predilección, saltan a la vista los ecos de su pensamiento comenzando por el epígrafe citado de Discusión: "Nuestra vida es una serie de adaptaciones, vale decir, una educación del olvido" (87). Partiendo de esas palabras, la posición de Bianciotti va un paso más allá, ya que para él es necesario rememorar y contar, porque el hombre es la suma de todo lo que le aconteció y sólo contando las experiencias vividas se crea la realidad. Kipling, pues, evoca aquellos momentos clave de su vida que lo convertirán no sólo en un famoso escritor, sino también y, a su pesar, en portavoz del Imperio Británico. El narrador razona con lógica borgeana:

Para dar un ideal común a gentes de todas las razas y religiones, basta un sentimiento simple, como el odio hacia otro país. La Historia es lenta para la vida de un hombre, y su economía, misteriosa: Inglaterra les procuraria un odio a su medida. Yo, sin saberlo, creyendo hacer lo contrario, heraldo de mi país, contribur a engendrarlo. Nadie conoce la finalidad, nadie sabe lo que hace (104).

Palabras éstas que recuerdan entre otros a cuentos como "El jardín de senderos que se bifurcan" y "Tema del traidor y el héroe," sintetizan también una realidad humana: el hombre no alcanzará a comprender la finalidad de muchas de sus acciones hasta el fin de su vida.

Como Borges, Kipling siente la necesidad de intentar una explicación humana del universo. En vez de la biblioteca infinita del ciego ilustre, el cuentista inglés ambiciona reducir el mundo a un alfabeto: "aun convencido de que ese alfabeto no podría encubrir sino un mundo de espejismos, de errores nunca lo que está detrás, y su Alfabeto"(106-107). Por lo visto Bianciotti no es más optimista que Borges en cuanto a la posibilidad de descubrir la causa primera.

En "Bonsoir les choses d'ici-bas" Bianciotti nos introduce al mundo de la creación literaria para reiterar preocupaciones formales características de su pensamiento. El cuento enfoca dos vidas de manera retrospectiva: la de un talentoso escritor francés de principios de sigloy la de un compañero de estudios, el narrador, dotado de sensibilidad estética, pero incapaz de crear. Ya al fin de su vida, el narrador recapitula datos biográficos significativos del escritor, especialmente del período escolar, momento en que se inicia la relación entre ambos en un internado en las afueras de París. El relato en primera persona nos permite conocer sólo un aspecto de la relación, pero dada la intención de Bianciotti, ésa es la que más importa.

Ser hombre de letras era la ambición secreta del narrador, pero, a edad temprana y en contacto con el enfermizo pupilo francés, comprende que el otro es el llamado a ser escritor. De inmediato se establece una amistad basada en intereses comunes, pero que genera la envidia del que se sabe inferior: 
No recuerdo si comprendí en aquel momento que me había vencido de una manera perdurable -que alguien en mí, alguien futuro, el que yo quería ser, se había rendido de verdad a él. Supe, en cambio, que le guardaría rencor, lo sentí nacer (227).

Siguiendo el ejemplo de tantas de las ficciones de Borges, Bianciotti desarrolla el cuento de manera que la relación entre los dos personajes asume las cualidades de una imagen proyectada por medio de un espejo. El narrador sólo adquiere conciencia de quien es por medio de su amigo y éste logra el objetivo al plasmar la identidad del otro en un libro. Cuando el escritor publica un libro que atribuye a un millonario peruano, el personaje narrador se reconoce y reacciona sugiriendo al autor que suprima algunos de los poemas caricaturales. Cinco años más tarde, el protagonista encuentra una nueva edición del libro. En ésta el prólogo biográfico había sido sustituído por un diario íntimo del millonario, que por un lado se deleita con los placeres que le brinda su fortuna $y$, por el otro, se halla dominado por el deseo de aprenderlo todo a través de los libros. El millionario es el narrador inmortalizado por medio de la palabra; la ferviente aspiración por el conocimiento, sin embargo, refleja al autor. El odio del protagonista hacia su antiguo compañero de colegio aumenta al sentirse disminuido en dicha caracterización, sin comprender que al combinar ambas personalidades se plasmaba literariamente la relación simbiótica entre ellos. Ese rencor se disipará años después durante la última visita a su rival, ya en su sillón de ruedas y próximo a la muerte. El escritor había legado su querida biblioteca a la alcaldía de la ciudad y las autoridades, con el pretexto de que habia goteras en la casa, van a recoger los libros. Los dos hombres presencian horrorizados mientras rápidamente la gente enviada vacía los anaqueles:

El viejo rencor, la envidia, el odio se apagaron de golpe en mí y me sentí aterrado. Juntos contemplamos el despojo;juntos vimos a sus amigos, los libros, irse antes de que él mismo se marchara.

En los salones devastados, en medio de las despobladas estanterías, sentí que detrás de aquel rostro estaban no sólo los libros que su amor había reunido, sino aquéllos, virtuales, que pujaban por componerse todavía en el. Las páginas se hallarían mezcladas, mezcladas sus frases, las sílabas, las letras. Todo sería puro caos de signos (235).

Aunque el escritor fallece posteriormente, su vida verdaderamente cesa a partir del cruel despojo, porque la pérdida elimina su poder creativo, lo cual es como si se lo hubiera condenado a muerte.

Significativamente el narrador termina sus días en Venecia, ciudad predilecta de Bianciotti que simboliza cultura y pasado ilustre. El protagonista se esfuerza en buscar su memoria, fragmento del subconsciente colectivo donde podrá hallar la respuesta al enigma de su existencia. En la memoria, según él, se encuentran los símbolos que llevamos en nosotros y la vamos buscando, sin 
saberlo, porque nos la ha legado la divinidad al nacer (236). Reflejando la importancia que la forma, la simetria y la arquitectura tienen en la obra de Bianciotti, el yo narrador aspira a integrar la ciudad a su memoria para poder verla un día, sin salir de su cuarto, detrás de los párpados, como Dios. Con recogimiento místico busca en la simetría laberíntica de sus canales, iglesias y palacios la respuesta que le permita escapar de la nada. Pero la ciudad es tan inasible como el simulacro de su imagen reflejada en las aguas y, en consecuencia, Venecia se convierte finalmente en sinónimo de infierno, en símbolo de la limitación humana. El personaje, aislado de todo contacto humano, frustrado y confundido, termina por rechazarse a sí mismo al rechazar la imagen que le devuelve el espejo.

"El oro de la memoria", en contraste con los cuentos examinados, no es de carácter evocativo, pero enfoca de lleno el tema de la memoria, de acuerdo a la concepción de Bianciotti. Reaparece pues el concepto del hombre que se esfuerza en recordar todo aquello que, configurando su pasado, brinde asidero a su presente y futuro. El protagonista, en la última etapa de su vida, se imagina un tablero de damas en el cual cada espacio se va ocupando con figuras privilegiadas de su memoria:

... había inventado ese rigor de la memoria para después del cuerpo, a fin de que esos momentos escogidos le ayudaren a acordarse de él mismo ... (175).

Especie de rompecabezas que debe completarse antes de su muerte, el hombre había conseguido resucitar figuras, hechos, dichas o desdichas, pero quedaba un escaque vacío, una casilla blanca, que ocupaba el centro entre las piezas.

Se inicia un juego simétrico en que, a través de sus sueños, el protagonista, como el personaje borgeano de "Las ruinas circulares," conjura la imagen del otro que también tiene un espacio por llenar. Poco a poco los sueños le permiten vislumbrar la imagen perdida de un joven pintor a quien había amado. El protagonista se lanza a la búsqueda del cuadro donde espera hallar la correspondencia con su casilla vacía. El relato narra los altibajos de la búsqueda del cuadro que se halla en posesión de la madre del pintor, paciente en un manicomio.

Como en "Bonsoir les choses d'ici-bas," reencontrar el pasado significa reencontrarse consigo mismo, o con el otro, con ese yo que emerge como una imagen invertida, semejante a la producida por un espejo. En ambos cuentos se entabla una estrecha relación entre el protagonista y el otro personaje que es un creador, reflejando las aspiraciones o los deseos íntimos de los protagonistas por acercarse al hechoestético. Una vez que el personaje creador ha desaparecido, lo único que permanece es el recuerdo, especie de archivo de los acontecimientos de donde el protagonista extrae lo que considera primordial para crear su memoria, su realidad. Al fin de su vida el protagonista necesita el apoyo de aquéllo que fue o cree haber sido; la memoria es lo único que puede salvarlo de la nada porque, como le explica a la madre del pintor: 
Los seres que he querido hoy no son nadie. Quedan ciertas palabras, ciertos gestos que fueron de uno o de otro, y hoy son de cualquiera (196-197).

Así como en "Bonsoir" el narrador llega a admitir su incapacidad de recrear a Venecia con los ojos cerrados como la divinidad, el protagonista de "El oro de la memoria" comprende, cuando llega a ver el cuadro deseado, que está destinado a sumergirse en la nada:

La forma y el color se confundían en la percepción, y todo parecía volcarse hacia la posesión de lo que el pintor había querido ver y no habia visto: todo su universo de formas estrictas, de rostros, de arquitecturas, de simetrías y perspectivas atónitas, deploraba la ausencia del centro virtual del cuadro, de ese fragmento que debía sostenerlo y justificarlo: en lo alto de la tela, donde antaño solía aparecer Dios o su presagio, la luz, no había nada más que un cuadrángulo virgen, la realidad pobre de la tela embadurnada de blanco (198199).

El descubrimiento del personaje completa el círculo que se inició al percibir la casilla en blanco. El espacio en blanco de su tablero imaginario encuentra su correspondencia en el otro espacio en blanco, el del creador, que a través de los años ha tratado de mantener en secreto su fracaso del ser querido. La inhabilidad de éste de completar su visión, deja trunca su creación en un aspecto vital ya que el espacio en blanco corresponde a Dios o a la luz que daría significado al resto del cuadro. La revelación es fatal para el protagonista para quien el descubrimiento significa ser absorbido por la blancura, o sea por la nada.

En su entrevista con José Luis Reina, Bianciotti concuerda con éste en que él, como escritor, reflexiona constantemente sobre el misterio detrás de la fuerza que impulsa a todo creador a expresarse. En los cuentos que hemos analizado, el poder de la creación es la fuerza motriz que genera la temática de los relatos. En "Las iniciales" el escriba homenajea a su madre con el único medio para el que está capacitado: la palabra. En su evocación resalta el hecho que su inclinación a la literatura era inexplicable y desde pequeño se había diferenciado de sus numerosos hermanos. En "Bagheera" el protagonista se refiere al momento en que descubre el poder de la escritura, estableciendo también la cualidad suprema de la literatura: "la colaboración entre la fantasía, el lenguaje y el arte de la imprenta, reaviva en cualquier hombre la ilusión de su eternidad" (97). La temática de "Bonsoir" enfoca la frustración del protagonista que ambiciona el destino de creador, pero que sólo está llamado a ser testigo de quien posee ese atributo. Finalmente, en "El oro de la memoria," dos vidas que brevemente se tocan dejan una indeleble y mutua huella en sus destinos por medio de una creación, en este caso una pintura, que resulta imposible de completar.

El novelista colombiano Rafael H. Durán en un artículo sobre Bianciotti menciona que el escritor argentino no oculta su entusiasmo por la nostalgia 
como factor protagonista de sus obras. Esa nostalgia emana naturalmente de la fuerza evocativa que mucha de la narrativa de Bianciotti posee. Cuando el único porvenir del hombre es, según el escritor, el pasado y la tradición, no es de extrañar que la sublimación del pretérito sea fundamental para sus criaturas. El hombre maduro encuentra asidero en lo que fue; su aprendizaje vital no sólo es base de lo que es, sino que, al fin de la vida, le permite enfrentarse con lo desconocido en el más allá. En sus relatos, la memoria permite que el personaje identifique a dos personas en diferentes fases de su vida, y ya no basta que la que narra cuente una acción, sino que debe revelar una filosofía de la vida que justifique el haberse puesto a evocar. Esa manera de encarar el relatole permite además a Bianciotti entretejer elementos culturales estructuradores que han dejado un sello particular en su ficción. Durán los identifica acertadamente: el recurso de la cita velada, el homenaje a otros autores sin mencionar nombres, Borges, en nuestra opinión, uno de los más obvios, títulos u otros detalles fácilmente reconocibles, todo lo cual constituye una especie de mensaje oculto al lector que tenga respecto al dato cultural citado la misma aceptación, idéntico gusto o similar sensibilidad estética (25).

El universo de Bianciotti revela a un escritor de sensiblidad estética que, consciente de sus lazos con la tradición cultural europea, de la cual es heredero y estandarte, recrea ambientes íntimos, nostálgicos, poblados por criaturas inclinadas a la introspección que examinan sus vidas como un creador su obra. Como Mallarmé, Bianciotti parece decirnos "el mundo existe para llegar a un libro", el libro incesante que para Borges era la única cosa del mundo (Borges 115). 


\section{OBRAS CITADAS}

Anderson Imbert, Enrique. Teoría y técnica del cuento. Buenos Aires: Marymar, 1979.

Bianciotti, Héctor. El amor no es amado.. Barcelona: Tusquets, 1983.

Borges, Jorge Luis. Otras inquisiciones. Madrid: Alianza, 1976.

Moreno Durán, Rafael Humberto. "La travesía nocturna de la escritura." Quimera, enero 1981: 22-25.

_.. "Entrevista con Héctor Bianciotti." Quimera, enero 1981: 26-29.

Reina, José Luis. “La isla íntima. Entrevista con Héctor Bianciotti." Quimera, febrero 1988: 56-6l. 
